\title{
A Proof of Concept: Does Beta-tricalcium Phosphate in a Hydroxyl Sulphate Matrix Reduce Cavity Size and Problems in Revision Mastoidectomy Patients
}

\section{Tawakir Kamani*, Wai Sum Cho and John Birchall}

Department of Otolaryngology, Royal Derby Hospital, UK

*Corresponding Author: Tawakir Kamani, Department of Otolaryngology,

Royal Derby Hospital, UK.
Received: July 24, 2020

Published: August 25, 2020

(C) All rights are reserved by Tawakir

Kamani., et al.

\begin{abstract}
Introduction: Surgical management of cholesteatoma consists of mainly canal wall up (CWU) or canal wall down (CWD) mastoidectomy. CWD mastoidectomy is associated with lower rate of recidivism but requiring long-term care. The associated mastoid cavity from CWD surgery can be obliterated to reduce cavity size and subsequent long-term care. We aimed to assess suitability of betatricalcium phosphate in a hydroxyl sulphate matrix (CPHSM), a biopolymer, in mastoid obliteration.

Methods: Research ethics approval was obtained. A prospective observational study of six patients that required revision mastoidectomy was undertaken with a follow-up period of a year. Study outcome measures included ear canal volume, pure-tone audiometry and documentation of any post-operative infections in the operated ear.

Results: A total of six patients were included in the study with one patient eventually excluded as recurrent cholesteatoma was identified intra-operatively. Three (60\%) patients had extrusion or resorption of the polymer at 1 year's follow-up. The polymer integrated into the mastoid cavity in one (20\%) patient who did not have any further infections. The remaining patient did not attend long-term follow-up. There was no change in pre and post-operative hearing thresholds.

Conclusion: CPHSM in its current form is not suitable for routine use. There is no evidence of ototoxicity and CPHSM was easy to use but there was a high rate of early infection, extrusion and resorption.
\end{abstract}

Keywords: Canal Wall Up (CWU); Cavity; Beta-tricalcium Phosphate

\section{Introduction}

One of the main causes of chronic ear disease is the presence of cholesteatoma. The management of cholesteatoma is mainly surgical with the option of canal wall up (CWU) or canal wall down (CWD) mastoidectomy. There are advantages and disadvantages of either approach. In CWD mastoidectomy the posterior part of the canal wall is removed thus giving better access and visualisation to the middle ear and mastoid. This results in a lower rate of recidivism compared to CWU mastoidectomy [1]. However, removing the posterior canal wall in CWD surgery leads to change in anatomy, creating a cavity, and subsequent need for periodical cleaning of the cavity necessitating long-term follow-up [2]. Due to change in anatomy, there is an increased risk of infections, vertigo due to temperature changes, difficulty fitting a hearing aid and water intolerance [3].

Surgical removal of cholesteatoma through a closed technique preserving the canal wall is usually called combined approach tympanomastoidectomy (CAT). The mainstay of a CAT approach is to maintain the posterior ear canal wall integrity allowing a physiological ear canal without a cavity. However, removal of cholestea- 
toma from some middle ear crevices such as the sinus tympani is often challenging and CWU surgeries are associated with a higher incidence of recidivism requiring a re-look procedure in about 12 months [1]. Diffusion weighted magnetic resonance imaging (MRI) provides an alternative to second look surgery with sensitivity of $89.8 \%$ and specificity $94.6 \%$ [4]. However, this technique is still relatively new and there may be inter-departmental variation in the sensitivity and specificity of using this imaging modality to identify cholesteatoma [5].

To obtain a better view of the middle ear, the cholesteatoma can be exteriorised and depending on the extent of disease, a cavity will be created from the ear canal into the mastoid. In limited disease, partial removal of the ear canal wall by atticotomy or atticoantrostomy can be performed and the small defect created can be reconstructed with fascia and cartilage graft. For the more extensive cholesteatoma extending and involving the whole of the mastoid cavity, a canal wall down approach through a modified radical mastoidectomy (MRM), in which the posterior canal wall is removed to access disease within the mastoid leaving the patient with a large EAC and a mastoid cavity. Patients with a mastoid cavity are at a higher risk of recurrent infections and a discharging ear [6].

Various methods have been employed to reduce cavity sizes through mastoid obliteration with the aim of combating associated cavity problems $[6,7]$. Mastoid obliteration is also based on the principle of combining the advantages of both CWU and CWD [8]. Various autologous materials such as cartilage, cartilage chips, musculoperiosteal flaps, bone chip and bone pate have been used to reduce or obliterate the mastoid cavity either as a single stage procedure or in recurrent cavity infections $[6,9]$.

Different biomaterials have also been tried on the basis that they should be non-absorbable, non-reactive and integrate. A number of techniques that used both autogenous tissue and hydroxyapatite (HA) cement have been reported and found early failure in the HA use due to displacement of the overlying fascial graft with inflammatory granulation and infections $[10,11]$. HA as a substance can be messy to use and although can fill holes, it is unable to be used to sculpt cavity hence failing to reconstruct the EAC posterior wall. HA is currently widely used for partial obliteration of mastoid cavities and has to date shown problems with prolonged inflammatory reactions and, finally, extrusions [12].
The commonest used bone substitutes are alloplasts, which are synthetic, inorganic, and biocompatible bone substitutes that act as defect fillers. They aid bone regeneration through osteoconduction. Biopolymers have been engineered such that autologous bone can grow in and replace and have been used in orthopaedics and maxillofacial surgery to facilitate new bone growth. One such biopolymer is beta-tricalcium phosphate in a hydroxyl sulphate matrix (CPHSM) that acts as a scaffold for bone proliferation as it is slowly resorbed by osteoclasts and replaced by osteoblasts that grow directly in contact with the mineral [13]. The hydroxyl matrix is bacteriostatic and pyrogen free, creating a nano-porous cell-occlusive membrane preventing the early invasion of unwanted soft tissue [13]. It is simple to use, mouldable, and sets to form a hard but resorbable osteo-conductive material [13]. Its use has been successfully reported in a clinical case study for maxillary sinus floor augmentation which showed that it was replaced totally by new mineralised bone [14]. It appears to have the properties of the ideal cavity filler as it stimulates growth of new bone at the surgical site and reabsorbs at a rate equal to the deposition rate of new bone, does not stimulate an inflammatory response or have unwanted systemic or local effects [14].

We report a proof of concept trial to establish whether CPHSM is safe and effective in reduction of mastoid cavity size and hence prevent mastoid cavity problems.

\section{Methods}

Following Research Ethics Committee (REC) approval, a prospective observational study of six patients that required revision mastoidectomy was undertaken with a follow-up period of a year.

The study outcome measures included ear canal volume, puretone audiometry and documentation of any post-operative infections in the operated ear.

Six patients that were candidates for revision mastoid surgery were identified in clinic by members of the research team and informed about the study. Adults that consented to participate in would have CPHSM applied to the mastoid to obliterate the cavity and reconstruct the posterior ear canal at the time of surgery. The senior author performed all surgeries.

The exclusion criteria were patients under 18 years of age, nonEnglish speakers and patients with co-morbidities that could put 
them at higher risk of post-operative infection. Patients with history of bilateral ear surgeries were excluded as well to allow a comparative normal ear canal for measurement of surgical outcome. Patients were reviewed at two weeks, two, six, eight and twelve months post-surgery.

\section{Results}

A total of six patients were included in the study with one patient eventually excluded as recurrent cholesteatoma was identified intra-operatively and the mastoid cavity was subsequently left open (Table 1). There was infection in the immediate post-operative period in two $(40 \%)$ patients. Two $(40 \%)$ patients had migration and subsequent extrusion of the polymer and one patient had resorption of the polymer at 1 year's follow-up. The polymer integrated into the mastoid cavity in one (20\%) patient who did not have any further infections with his mastoid cavity. One patient did not attend long-term follow-up.

All patients had unchanged hearing thresholds pre- and postoperatively. Ear canal volume was largely unchanged in patients where the polymer had extruded and resorped. We were unable to accurately measure ear canal volume for patient 2 (Table 1) due to tympanic membrane perforation. The cavity was clinically smaller than pre-operative appearance.

Patient 1 and 5 (Table 1), despite extrusion of the polymer, did not have any further mastoid cavity infection on long term followup. Patient 3 had granulation within the mastoid cavity and chronic inflammation but declined further intervention and was lost to long-term follow-up.

\begin{tabular}{|c|c|c|c|c|c|}
\hline Patient & History & Side & Surgery & Follow up & $\begin{array}{l}\text { Long term } \\
\text { (more than } 12 \text { months) }\end{array}$ \\
\hline 1 & $\begin{array}{l}\text { Canal wall down } \\
\text { mastoidectomy } 1999 \text { and } \\
\text { had recurrent cavity infec- } \\
\text { tions }\end{array}$ & Left & $\begin{array}{c}2013 \text { revision } \\
\text { mastoidectomy and } \\
\text { obliteration with } \\
\text { CPHSM }\end{array}$ & $\begin{array}{l}\text { Extrusion of CPHSM } 3 \\
\text { weeks post surgery }\end{array}$ & $\begin{array}{l}\text { No further infection, admitted } \\
\text { size } 3 \text { speculum, healthy cavity }\end{array}$ \\
\hline 2 & $\begin{array}{l}\text { Canal wall down } \\
\text { mastoidectomy } 2012 \text { and } \\
\text { revision surgery in } 2013\end{array}$ & Left & $\begin{array}{c}2014 \text { revision } \\
\text { mastoidectomy and } \\
\text { obliteration with } \\
\text { CPHSM }\end{array}$ & $\begin{array}{l}\text { Infected cavity which } \\
\text { settled at } 12 \text { week } \\
\text { post surgery review }\end{array}$ & $\begin{array}{c}\text { No further infection, admitted } \\
\text { size } 3 \text { speculum, cavity reduced } \\
\text { in size }\end{array}$ \\
\hline 3 & $\begin{array}{c}\text { Canal wall down } \\
\text { mastoidectomy } 2002\end{array}$ & Left & $\begin{array}{c}2014 \text { revision } \\
\text { mastoidectomy and } \\
\text { obliteration with } \\
\text { CPHSM }\end{array}$ & $\begin{array}{l}\text { Infected cavity which } \\
\text { settled at } 12 \text { week } \\
\text { post surgery review }\end{array}$ & $\begin{array}{l}\text { Resorption of CPHSM and } \\
\text { granulation within mastoid } \\
\text { cavity }\end{array}$ \\
\hline 4 & $\begin{array}{l}\text { Canal wall down } \\
\text { mastoidectomy from a } \\
\text { different centre }\end{array}$ & Right & $\begin{array}{c}2014 \text { revision } \\
\text { mastoidectomy and } \\
\text { obliteration with } \\
\text { CPHSM }\end{array}$ & Healthy ear & $\begin{array}{l}\text { Did not attend long term follow } \\
\text { up }\end{array}$ \\
\hline 5 & $\begin{array}{c}\text { Canal wall down } \\
\text { mastoidectomy 1972, } \\
\text { revision surgeries 2011, } \\
2013\end{array}$ & Right & $\begin{array}{c}2014 \text { revision } \\
\text { mastoidectomy and } \\
\text { obliteration with } \\
\text { CPHSM }\end{array}$ & $\begin{array}{l}\text { No infection but } \\
\text { polymer noted to be } \\
\text { migrating anteriorly } \\
\text { with subsequent ex- } \\
\text { trusion at } 12 \text { weeks }\end{array}$ & $\begin{array}{l}\text { No further infection, admitted } \\
\text { size } 3 \text { speculum, healthy cavity }\end{array}$ \\
\hline 6 & $\begin{array}{c}\text { Combined approach } \\
\text { tympanomastoidectomy } \\
2005, \text { canal wall down } \\
\text { surgery } 2006 \text { and revision } \\
\text { surgery } 2011\end{array}$ & Left & $\begin{array}{c}2014 \text { revision } \\
\text { mastoidectomy } \\
\text { - excluded from study } \\
\text { due to recurrent } \\
\text { cholesteatoma }\end{array}$ & & \\
\hline
\end{tabular}

Table 1: Summary of patients who were included in the study and follow up findings. Size 3 speculums were $6 \mathrm{~mm}$ in diameter. 


\section{Discussion}

When CPHSM was used in the reconstruction of mastoid cavities, it was found to be user friendly and easily malleable to sculpt a posterior EAC wall through the reconstruction of the mastoid cavities. However, following surgery, we found that the material either re-absorbed or extruded and a number of the patients had early infection. Most patient's mastoid cavities persisted but due to the revision surgery, the cavity problems settled at one year. One patient failed to attend both planned clinical follow up and nurse led aural care clinic.

One of the difficulties we encountered that affected our outcomes was that in discharging ears, tympanometry could not be obtained and hence unable to measure the ear canal volumes. Obtaining an accurate measurement of the hearing thresholds on pure tone audiometry is questionable in the presence of an infection. The use of the aural speculum as an alternative to determine the EAC size is an approximate and not wholly accurate of the total cavity volume. Although we had a number of patients with infections post surgery, we found that it did not affect the hearing thresholds of the participants.

Mastoid obliteration is an important technique in cholesteatoma surgery with reports of good results using autologous materials [7-10]. Ezzat et al. performed a comparative study using autologous materials against synthetic materials (titanium mesh and bioglass) to obliterate the cavity and did not find a significant difference [15]. However, there are reports where alloplastic materials (hydroxyapatite cement, glass ionomer cement) failed to integrate, caused continued infections and even bony erosions necessitating further surgery to remove the material $[11,16]$. Our experience with CPHSM showed in general, this material failed to integrate and caused early infection in most cases. There was only one case where the CPHSM appeared to integrate and the patient had a dry ear post obliteration surgery.

There is also rising popularity of performing endoscope assisted mastoid surgery which allow visualisation of areas of the middle ear and mastoid where otherwise would have required removal of the canal wall via a microscopic technique [17]. Nogueira and Cohen found that the recidivism rate to be similar to patients who had a CWD approach due to improved visualization with the endoscope [17]. With increased popularity of this technique, mas- toid obliteration may be required in fewer cases in the future.

\section{Conclusion}

CPHSM in its current form is not suitable for routine use. There is no evidence of ototoxicity and CPHSM was easy to use but there was a high rate of early infection, extrusion and resorption.

\section{Bibliography}

1. Kerckhoffs KGP., et al. "The disease recurrence rate after the canal wall up or canal wall down technique in adults". Laryngoscope (2016).

2. Khalil HS and Windle-Taylor PC. "Canal wall down mastoidectomy: A long term commitment to the outpatients?" BMC Ear, Nose and Throat Disorders (2003).

3. Tomlin J., et al. "Surgical technique and recurrence in cholesteatoma: A meta-analysis". Audiology and Neurotology 18 (2013): 135-142.

4. Muzaffar J., et al. "Diffusion-weighted magnetic resonance imaging for residual and recurrent cholesteatoma: a systematic review and meta-analysis". Clinical Otolaryngology (2017).

5. Lingam RK., et al. "Non-echoplanar diffusion weighted imaging in the detection of post-operative middle ear cholesteatoma: navigating beyond the pitfalls to find the pearl". Insights Imaging (2016).

6. Harris AT., et al. "Pooled analysis of the evidence for open cavity, combined approach and reconstruction of the mastoid cavity in primary cholesteatoma surgery". The Journal of Laryngology and Otology 130.3 (2016).

7. Alves RD., et al. "Mastoid Obliteration with Autologous Bone in Mastoidectomy Canal Wall Down Surgery: A Literature Overview". International Archives of Otorhinolaryngology 20.1 (2016): 076-083.

8. Roberson JB., et al. "Mastoid obliteration: Autogenous cranial bone pÂte reconstruction". Otology and Neurotology 24.2 (2003): 132-140.

9. Lee HJ., et al. "Canal reconstruction and mastoid obliteration using floating cartilages and musculoperiosteal flaps". Laryngoscope (2017). 
10. Minatogawa T., et al. "Evaluation of mastoid obliteration surgery". American Journal of Otology (1995).

11. Mahendran S and Yung MW. "Mastoid obliteration with hydroxyapatite cement: The Ipswich experience". Otology and Neurotology 25 (2004): 19-21.

12. Punke C., et al. "Experimental studies on a new highly porous hydroxyapatite matrix for obliterating open mastoid cavities". Otology and Neurotology 29.6 (2008): 807-811.

13. Eleftheriadis E., et al. "Osteogenic activity of $\beta$-tricalcium phosphate in a hydroxyl sulphate matrix and demineralized bone matrix: a histological study in rabbit mandible". Journal of Oral Science 52.3 (2010): 377-384.

14. Smeets R., et al. "A new biphasic osteoinductive calcium composite material with a negative Zeta potential for bone augmentation". Head and Face Medicine 5 (2009).

15. Ezzat AEM., et al. "Comparison of natural and synthetic materials to improve hearing after obliteration of the mastoid cavity". Journal of Hearing Science 4.4 (2015): OA36-41.

16. Harrison L., et al. "Clinical case series describes a contraindication for SerenoCem GranulesTM in mastoid obliteration: Our experience in sixty-four patients". Clinical Otolaryngology (2017).

17. Nogueira JF and Cohen MS. "Combined endoscopic and microscopic approaches to cholesteatoma". Operative Techniques in Otolaryngology-Head and Neck Surgery 28.1 (2017): 36-38.

\section{Assets from publication with us}

- Prompt Acknowledgement after receiving the article

- Thorough Double blinded peer review

- Rapid Publication

- Issue of Publication Certificate

- High visibility of your Published work

Website: www.actascientific.com/

Submit Article: www.actascientific.com/submission.php

Email us: editor@actascientific.com

Contact us: +919182824667

Citation: Tawakir Kamani., et al. "A Proof of Concept: Does Beta-tricalcium Phosphate in a Hydroxyl Sulphate Matrix Reduce Cavity Size and Problems in Revision Mastoidectomy Patients". Acta Scientific Otolaryngology 2.9 (2020): 14-18. 